\title{
The rumen microbial metagenome associated with high methane production in cattle
}

\author{
R. John Wallace ${ }^{1 *}$, John A. Rooke ${ }^{2}$, Nest McKain ${ }^{1}$, Carol-Anne Duthie ${ }^{2}$, Jimmy J. Hyslop ${ }^{2}$, David W. Ross²,
} Anthony Waterhouse ${ }^{2}$, Mick Watson ${ }^{3 \dagger}$ and Rainer Roehe ${ }^{2+}$

\begin{abstract}
Background: Methane represents $16 \%$ of total anthropogenic greenhouse gas emissions. It has been estimated that ruminant livestock produce ca. $29 \%$ of this methane. As individual animals produce consistently different quantities of methane, understanding the basis for these differences may lead to new opportunities for mitigating ruminal methane emissions. Metagenomics is a powerful new tool for understanding the composition and function of complex microbial communities. Here we have applied metagenomics to the rumen microbial community to identify differences in the microbiota and metagenome that lead to high- and low-methane-emitting cattle phenotypes.

Methods: Four pairs of beef cattle were selected for extreme high and low methane emissions from 72 animals, matched for breed (Aberdeen-Angus or Limousin cross) and diet (high or medium concentrate). Community analysis was carried out by qPCR of $16 \mathrm{~S}$ and $18 \mathrm{~S}$ rRNA genes and by alignment of Illumina HiSeq reads to the GREENGENES database. Total genomic reads were aligned to the KEGG genes databasefor functional analysis.

Results: Deep sequencing produced on average $11.3 \mathrm{~Gb}$ per sample. 16S rRNA gene abundances indicated that archaea, predominantly Methanobrevibacter, were $2.5 \times$ more numerous $(P=0.026)$ in high emitters, whereas among bacteria Proteobacteria, predominantly Succinivibrionaceae, were 4-fold less abundant ( 2.7 vs. $11.2 \%$; $P=0.002$ ). KEGG analysis revealed that archaeal genes leading directly or indirectly to methane production were 2.7 -fold more abundant in high emitters. Genes less abundant in high emitters included acetate kinase, electron transport complex proteins RnfC and RnfD and glucose-6-phosphate isomerase. Sequence data were assembled de novo and over 1.5 million proteins were annotated on the subsequent metagenome scaffolds. Less than half of the predicted genes matched matched a domain within Pfam. Amongst 2774 identified proteins of the 20 KEGG orthologues that correlated with methane emissions, only 16 showed $100 \%$ identity with a publicly available protein sequence.
\end{abstract}

Conclusions: The abundance of archaeal genes in ruminal digesta correlated strongly with differing methane emissions from individual animals, a finding useful for genetic screening purposes. Lower emissions were accompanied by higher Succinovibrionaceae abundance and changes in acetate and hydrogen production leading to less methanogenesis, as similarly postulated for Australian macropods. Large numbers of predicted protein sequences differed between high- and low-methane-emitting cattle. Ninety-nine percent were unknown, indicating a fertile area for future exploitation.

Keywords: Archaea, Illumina, Metagenomics, Rumen, Succinovibrionaceae

\footnotetext{
* Correspondence: john.wallace@abdn.ac.uk

'Equal contributors

'Rowett Institute of Nutrition and Health, University of Aberdeen, Bucksburn, Aberdeen AB21 9SB, UK

Full list of author information is available at the end of the article
}

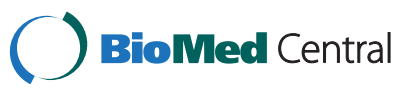

(c) 2015 Wallace et al. Open Access This article is distributed under the terms of the Creative Commons Attribution 4.0 International License (http://creativecommons.org/licenses/by/4.0/), which permits unrestricted use, distribution, and reproduction in any medium, provided you give appropriate credit to the original author(s) and the source, provide a link to the Creative Commons license, and indicate if changes were made. The Creative Commons Public Domain Dedication waiver (http://creativecommons.org/publicdomain/zero/1.0/) applies to the data made available in this article, unless otherwise stated. 


\section{Background}

Methane is a greenhouse gas (GHG) with a global warming potential 28 -fold that of carbon dioxide [1]. It is responsible for $16 \%$ of total anthropogenic greenhouse gas emissions [2]. Ruminants are the major producers of methane emissions from anthropogenic activities, accounting for $37 \%$ of total GHG from agriculture in the UK [3]. Lowering methane emissions has therefore become a major priority in ruminant livestock production, with many different strategies having been proposed to mitigate emissions, including different dietary formulations, chemical and biological feed additives, chemogenomics and antimethane vaccines [4-6]. Research is also under way to determine the extent to which the animal itself has control over its ruminal microbiota, with the intention that, if the trait is heritable, low-methane livestock phenotypes may form the basis of a breeding programme to produce ruminants with a smaller environmental footprint [7]. If any of the strategies proves to be successful, benefits may be anticipated in energy retention by the animal $[3,8]$.

Methane, although considered to be an atmospheric pollutant, is a natural product of anaerobic microbial fermentation [9]. The rumen is an anaerobic microbial ecosystem in which a dense mixture of protozoa, bacteria and anaerobic fungi convert carbohydrates to short-chain, volatile fatty acids (VFA), which are absorbed by the animal and used in energy metabolism and protein synthesis. Hydrogen is formed as a result of fermentation, and it is used by methanogenic archaea to reduce $\mathrm{CO}_{2}$ to methane [10]. Hydrogenotrophic methane production is quantitatively the most important source of methane, although methylotrophic methanogenesis also occurs, forming methane from molecules like methylamine [11].

Deep sequencing of DNA extracted from complex microbial communities enables many aspects of microbial ecology to be determined. Metagenomics allows the abundance of all genes present in the microbial community to be determined and metabolic pathways to be predicted. The first reports of metagenomic analysis of ruminal digesta demonstrated the power of the technology, focussing in functional terms on fibrolytic enzymes [12-14]. Since then, several further reports have appeared, applying various metagenomics methods again to fibrolytic enzymes [15-17], and to lipases $[18,19]$, virulence and antibiotic resistance genes [20], polyphenol oxidase [21], CRISPR elements [22] and secretome proteins [23].

In the present paper, we apply metagenomics to analyse the root causes of different methane emissions in high- and low-emitting beef cattle. A recent metagenomic analysis of high- and low-emitting sheep found correlations between the metatranscriptome rather than gene abundance and methane emissions in sheep [24], contrary to the expectation that methanogenic activity should be proportional to the abundance of methanogenic archaea and/or $\mathrm{H}_{2}$-producing microorganisms [25]. Several other studies have failed to find such a relationship [6, 26-28]. The present study was undertaken to investigate the comparative metagenomics of high- and low-emitting beef steers. The animals were selected as pairs of the highest and lowest emitters from an experimental group comprising two cattle breeds each receiving one of two diets differing in concentrate content. Hydrogen and methane emissions from the whole group were reported previously [29], as was a preliminary correlation between methane emissions and the ratio of total ruminal archaea to total bacteria [30]. Unlike the other studies, archaeal gene abundances in ruminal digesta, including $16 \mathrm{~S}$ rRNA genes, corresponded with the extreme differences in methane emissions from beef cattle. Furthermore, distinctive differences in the microbiomes and metagenomes of high- and lowemitting cattle were identified.

\section{Results}

\section{Methane emissions}

Thirty-six Aberdeen Angus and 36 Limousin cross bred steers received one of two diets, one mainly concentratebased and the other a forage-concentrate-based diet, with forage:concentrate ratios (DM basis) of 8:92 and 48:52, respectively. All cattle came from the same breeding herd population and were kept in the identical farm environment throughout their lifetimes. Methane emissions were measured in respiration chambers and samples of ruminal digesta were obtained at slaughter 1-2 weeks afterwards [30]. Four pairs of digesta samples for each breed/diet combination were selected, based on being which were obtained from animals showing the highest and lowest $\mathrm{CH}_{4}$ emissions when expressed in terms of DM intake (Table 1). On average, the high emitters produced $1.88 \times$ more $\mathrm{CH}_{4}$ than low emitters. Average feed intake was similar between high and low emitters, at 10.59, SE 1.03, kg DM intake/d and 10.68, SE 1.03, kg DM intake/d, respectively.

\section{Microbial community analysis}

qPCR of specific regions of $16 \mathrm{~S}$ and $18 \mathrm{~S}$ rRNA genes enabled a characterisation of the broad features of the microbiome (Table 1). Although protozoa and Clostridium Cluster IV bacteria were on average $1.71 \times$ and $1.52 \times$ more abundant, respectively, in high emitters and Clostridium Cluster IV and Bacteroidetes were $0.72 \times$ and $0.71 \times$ as abundant, the only difference that was statistically significant $(P=0.011)$ was a $2.40 \times$ higher archaeal abundance in high emitters. The proportion of the abundance of archaeal to bacterial 16S rRNA genes (the A:B ratio $^{(30)}$ ) was on average $3 \%$ in low emitters and $9 \%$ in the high emitters. Bacteroidetes comprised $33.4 \%$ of the bacteria, while Clostridium Cluster IV and XIVa were 23.4 and $18.3 \%$, respectively. Proteobacteria appeared to be 
Table 1 Estimation of abundance of 185 and 165 rRNA genes by qPCR in four pairs of steers with extreme methane emissions

\begin{tabular}{|c|c|c|c|c|c|c|c|c|c|c|c|c|}
\hline & \multicolumn{2}{|c|}{ AA/Conc } & \multicolumn{2}{|l|}{ L/Conc } & \multicolumn{2}{|l|}{ AA/Med } & \multicolumn{2}{|l|}{ L/Med } & \multicolumn{2}{|l|}{ Mean } & \multirow[t]{2}{*}{$P$ value } & \multirow{2}{*}{$\begin{array}{l}\text { Ratio } \\
(\mathrm{H} / \mathrm{L})\end{array}$} \\
\hline & Low & High & Low & High & Low & High & Low & High & Low & High & & \\
\hline $\mathrm{CH}_{4}$ (g/kg DM intake) & 7.63 & 18.14 & 9.29 & 20.13 & 17.41 & 32.42 & 19.37 & 30.37 & 13.43 & 25.26 & & 1.88 \\
\hline \multicolumn{13}{|c|}{ qPCR of 165 and 185 rRNA genes (copies/ng DNA) } \\
\hline Protozoa & 9395 & 8315 & 464 & 18865 & 500 & 24480 & 20940 & 1768 & 7825 & 13357 & 0.613 & 1.71 \\
\hline Bacteria & 923503 & 1026155 & 964081 & 572312 & 891432 & 575574 & 563798 & 595201 & 835704 & 692311 & 0.329 & 0.83 \\
\hline Archaea & 23269 & 72076 & 21459 & 40242 & 19662 & 54880 & 37006 & 75912 & 25349 & 60777 & 0.011 & 2.40 \\
\hline Cluster IV & 110080 & 278085 & 114411 & 76922 & 135520 & 221092 & 175738 & 236213 & 133937 & 203078 & 0.201 & 1.52 \\
\hline Cluster XIVa & 193249 & 119584 & 173592 & 99130 & 181399 & 89060 & 97723 & 155352 & 161491 & 115782 & 0.279 & 0.72 \\
\hline Bacteroidetes & 337544 & 276658 & 215824 & 299295 & 342174 & 134542 & 274886 & 122765 & 292607 & 208315 & 0.277 & 0.71 \\
\hline Proteobacteria & 3341 & a & 9783 & 1446 & 21270 & 2085 & 4350 & 2489 & $11801^{\mathrm{a}}$ & $2007^{a}$ & 0.192 & 0.17 \\
\hline
\end{tabular}

Comparison of methane emissions ( $\mathrm{g} / \mathrm{kg} \mathrm{DM}$ intake) and the abundance of various bacterial taxa as determined by qPCR for 4 pairs of steers matched for breed and diet. AA Aberdeen Angus, $L$ Limousin. Conc, high concentrate diet; Med, mixed forage: concentrate diet. DMI dry matter intake

${ }^{a}$ Sample produced an abnormal melt curve. The mean was based on the three other pairs

less abundant in high emitters, but DNA from one sample proved impossible to amplify to produce an acceptable melt curve.

Genomic DNA extracted from the same samples was also submitted for deep sequencing using the Illumina HiSeq platform. Reads mapping to $16 \mathrm{~S}$ rRNA gene sequences were assigned to taxonomic groups at kingdom, phylum and genus levels (Table 2). Archaeal abundance was, as with qPCR above, calculated relative to bacterial abundance. As with qPCR, the archaea were more abundant $(2.49 \times ; P=0.046)$ in the high emitters, reflected in similar differences in Euryarchaeota at the phylum level and Methanobrevibacter at genus level. Methanobrevibacter abundance varied from 1.9 to $11.0 \%$ compared to total bacterial counts and was $2.54 \times$ more abundant $(P=0.017)$ in high emitters. Methanosphaera were much less abundant (0.01 to $0.13 \%)$, while Methanobacterium (0 to $0.03 \%$ ) were not identified or of very low abundance still (Table 2). Methanosphaera were $2.44 \times$ more abundant $(P=0.014)$ in high emitters. Thermoplasmata-related archaea were less abundant than other archaeal genera and their abundance was greater in the high emitter in only three of the four pairs.

Among the bacteria, Firmicutes and Bacteroidetes were not different, in contrast to Proteobacteria, which were $0.24 \times$ less abundant in the high emitters $(P=0.002)$. Analysis of the Proteobacteria was only resolved to family level (Additional file 1: Table S1) due to short reads. Succinivibrionaceae were the most abundant in all samples, averaging $88 \%$ of Proteobacteria reads, average $97 \%$ in low emitters and $79 \%$ in high emitters. Synergistetes were $1.95 \times$ more abundant in high emitters $(P=0.022)$. At genus level, Desulfovibrio was the genus whose abundance differed most significantly $(P=0.001)$, being twice as numerous in the high emitters. Others that were different included Megasphaera, which was only $0.08 \times$ as abundant in high emitters $(P=0.006)$. Mitsuokella and Dialister were lower and Mogibacterium and Pyramidobacter higher $(P<0.05)$ in high emitters compared to low emitters.

The richness and relative abundance of the bacteria and archaeal genera did not change significantly between low and high emitting animals. Mean Shannon index was 3.17 for high and 2.98 for low emitting animals respectively. Mean Chao1 index estimated 170 genera for high and 172 low emitting animals respectively (Additional file 2: Table S2).

\section{Gene abundance analysis}

Reads were mapped to gene sequences in the KEGG [31] database and analysed (a) in a directed manner towards genes involved directly in methanogenesis, (b) in a directed manner towards genes involved in alternatives to methanogenesis, (c) in a directed manner towards genes involved in methane oxidation, and (d) in a global manner to compare the abundances of all annotated genes in the metagenome. The whole KEGG dataset can be seen in Additional file 3: Table S3. Statistical $P$ values in Additional file 3: Table S3 are uncorrected for multiple comparisons. When the data are discussed within their biological context, uncorrected $P$ values are quoted below. When multiple testing was accounted for in a partial least squares analysis, few significant differences due to KEGG genes were found (Table 3), but many of these were genes associated with methanogenesis or archaea, below. The genes identified in Table 3 to be important explained the variation in methane emissions by $88 \%$.

(a) Genes directly involved in methanogenesis. Genes encoding enzymes that are directly involved in methanogenesis [24] were analysed for their abundance in highand low-emitting cattle (Fig. 1). With the exception of the very low-abundance formate dehydrogenase $\beta$ subunit 
Table 2 Estimation of abundance of 165 rRNA genes in ruminal metagenomic sequences from four pairs of steers with extreme methane emissions (\% of mapped reads)

\begin{tabular}{|c|c|c|c|c|c|c|c|c|c|c|c|c|}
\hline & \multicolumn{2}{|c|}{ AA/Conc } & \multicolumn{2}{|c|}{ L/Conc } & \multicolumn{2}{|c|}{ AA/Med } & \multicolumn{2}{|l|}{ L/Med } & \multicolumn{2}{|l|}{ Mean } & \multirow[b]{2}{*}{$P$ value } & \multirow[b]{2}{*}{ Ratio $(\mathrm{H} / \mathrm{L}$} \\
\hline & Low & High & Low & High & Low & High & Low & High & Low & High & & \\
\hline \multicolumn{13}{|l|}{ Domain } \\
\hline Bacteria & 98.84 & 97.72 & 99.24 & 95.08 & 98.82 & 96.60 & 97.07 & 95.60 & 98.49 & 96.25 & 0.0455 & 0.98 \\
\hline Archaea & 1.16 & 2.28 & 0.76 & 4.92 & 1.18 & 3.40 & 2.93 & 4.40 & 1.51 & 3.75 & 0.0455 & 2.49 \\
\hline \multicolumn{13}{|l|}{ Bacteria } \\
\hline \multicolumn{13}{|l|}{ Phylum/Class } \\
\hline Firmicutes & 45.25 & 43.11 & 48.81 & 40.47 & 43.93 & 46.31 & 39.50 & 52.74 & 44.37 & 45.66 & 0.9866 & 1.03 \\
\hline Bacteroidetes & 36.21 & 40.06 & 25.70 & 45.33 & 34.53 & 36.47 & 49.98 & 31.64 & 36.61 & 38.38 & 0.3975 & 1.05 \\
\hline Proteobacteria & 11.93 & 3.71 & 17.15 & 4.44 & 13.17 & 1.92 & 2.56 & 0.83 & 11.20 & 2.73 & 0.0015 & 0.24 \\
\hline Actinobacteria & 1.88 & 1.38 & 1.90 & 1.10 & 1.01 & 1.02 & 0.57 & 1.17 & 1.34 & 1.17 & 0.1309 & 0.87 \\
\hline Cyanobacteria & 1.69 & 1.41 & 2.11 & 0.78 & 0.07 & 0.42 & 0.10 & 0.17 & 0.99 & 0.69 & 0.2421 & 0.70 \\
\hline Tenericutes & 0.73 & 2.27 & 1.79 & 1.27 & 1.65 & 2.48 & 0.86 & 1.87 & 1.25 & 1.97 & 0.2425 & 1.57 \\
\hline Spirochaetes & 0.46 & 3.65 & 1.27 & 0.54 & 1.39 & 0.89 & 0.55 & 1.15 & 0.92 & 1.56 & 0.5873 & 1.70 \\
\hline Lentisphaerae & 0.38 & 0.38 & 0.17 & 0.05 & 0.01 & 0.84 & 0.27 & 0.81 & 0.21 & 0.52 & 0.2491 & 2.50 \\
\hline TM7 & 0.12 & 0.31 & 0.06 & 0.05 & 0.50 & 0.38 & 0.60 & 0.49 & 0.32 & 0.31 & 0.5073 & 0.96 \\
\hline Synergistetes & 0.10 & 0.15 & 0.07 & 0.18 & 0.02 & 0.08 & 0.07 & 0.12 & 0.07 & 0.13 & 0.0215 & 1.95 \\
\hline Verrucomicrobia & 0.03 & 0.80 & 0.03 & 0.27 & 0.59 & 2.69 & 1.16 & 2.48 & 0.45 & 1.56 & 0.0695 & 3.44 \\
\hline Fibrobacteres & 0.02 & 0.09 & 0.13 & 0.04 & 1.65 & 1.92 & 0.05 & 0.85 & 0.46 & 0.73 & 0.2181 & 1.57 \\
\hline \multicolumn{13}{|l|}{ Genus } \\
\hline Prevotella & 54.11 & 38.09 & 45.60 & 57.30 & 50.04 & 39.96 & 56.00 & 30.41 & 51.44 & 41.44 & 0.3067 & 0.81 \\
\hline Butyrivibrio & 10.74 & 6.20 & 5.93 & 7.12 & 1.68 & 7.79 & 6.56 & 17.44 & 6.23 & 9.64 & 0.3757 & 1.55 \\
\hline Succiniclasticum & 5.59 & 6.26 & 14.34 & 11.05 & 6.83 & 4.21 & 6.34 & 4.84 & 8.28 & 6.59 & 0.1097 & 0.80 \\
\hline Bulleidia & 5.51 & 1.14 & 3.66 & 3.05 & 0.56 & 0.29 & 0.21 & 0.56 & 2.49 & 1.26 & 0.1487 & 0.51 \\
\hline Sharpea & 3.69 & 0.13 & 0.50 & 0.53 & 1.93 & 0.31 & 0.05 & 0.33 & 1.54 & 0.33 & 0.1228 & 0.21 \\
\hline Ruminococcus & 2.94 & 10.29 & 3.25 & 1.42 & 3.92 & 18.43 & 11.30 & 13.30 & 5.35 & 10.86 & 0.1288 & 2.03 \\
\hline YRC22 & 1.92 & 7.53 & 6.80 & 0.60 & 0.35 & 1.85 & 1.98 & 1.58 & 2.76 & 2.89 & 0.9796 & 1.05 \\
\hline Acidaminococcus & 1.65 & 0.21 & 2.47 & 0.47 & 0.05 & 0.01 & 0.01 & 0.00 & 1.04 & 0.17 & 0.0711 & 0.17 \\
\hline Coprococcus & 1.32 & 2.56 & 2.36 & 1.21 & 2.30 & 1.23 & 1.06 & 1.14 & 1.76 & 1.53 & 0.5241 & 0.87 \\
\hline Roseburia & 1.10 & 0.03 & 0.46 & 0.00 & 0.29 & 0.02 & 0.01 & 0.02 & 0.47 & 0.02 & 0.0484 & 0.04 \\
\hline Treponema & 0.87 & 7.80 & 3.07 & 0.85 & 2.97 & 1.45 & 0.81 & 2.47 & 1.93 & 3.14 & 0.6840 & 1.63 \\
\hline Megasphaera & 0.82 & 0.05 & 0.46 & 0.06 & 0.70 & 0.05 & 0.01 & 0.00 & 0.50 & 0.04 & 0.0056 & 0.08 \\
\hline Shuttleworthia & 0.78 & 0.49 & 2.81 & 0.47 & 0.15 & 0.04 & 0.14 & 0.10 & 0.97 & 0.27 & 0.1718 & 0.28 \\
\hline Pseudoramibacter_Eubacterium & 0.61 & 0.03 & 0.59 & 0.22 & 0.29 & 0.04 & 0.00 & 0.04 & 0.37 & 0.08 & 0.0118 & 0.22 \\
\hline Mogibacterium & 0.51 & 1.32 & 0.33 & 1.15 & 0.56 & 1.84 & 2.12 & 3.34 & 0.88 & 1.92 & 0.0407 & 2.17 \\
\hline CF231 & 0.43 & 1.11 & 0.04 & 0.19 & 0.88 & 1.74 & 1.28 & 1.00 & 0.66 & 1.01 & 0.0492 & 1.53 \\
\hline Bifidobacterium & 0.39 & 0.04 & 0.01 & 0.03 & 0.82 & 0.01 & 0.08 & 0.13 & 0.32 & 0.05 & 0.1569 & 0.17 \\
\hline Mitsuokella & 0.38 & 0.20 & 0.12 & 0.04 & 0.04 & 0.00 & 0.01 & 0.00 & 0.14 & 0.06 & 0.0375 & 0.43 \\
\hline Lactobacillus & 0.35 & 0.40 & 0.77 & 0.10 & 0.29 & 0.18 & 0.08 & 0.17 & 0.37 & 0.21 & 0.2347 & 0.57 \\
\hline Succinivibrio & 0.32 & 3.97 & 0.32 & 0.12 & 0.26 & 0.03 & 0.07 & 0.02 & 0.24 & 1.03 & 0.4932 & 4.32 \\
\hline Anaerostipes & 0.31 & 0.04 & 0.03 & 0.00 & 0.29 & 0.16 & 0.02 & 0.17 & 0.16 & 0.09 & 0.1915 & 0.56 \\
\hline Blautia & 0.29 & 0.39 & 0.17 & 0.17 & 0.87 & 0.38 & 0.22 & 0.56 & 0.39 & 0.37 & 0.7396 & 0.97 \\
\hline [Eubacterium] & 0.26 & 0.02 & 0.03 & 0.15 & 5.37 & 0.00 & 0.04 & 0.00 & 1.43 & 0.04 & 0.2619 & 0.03 \\
\hline
\end{tabular}


Table 2 Estimation of abundance of 16S rRNA genes in ruminal metagenomic sequences from four pairs of steers with extreme methane emissions (\% of mapped reads) (Continued)

\begin{tabular}{lcccccccccccc}
\hline Oscillospira & 0.24 & 0.50 & 0.25 & 0.26 & 0.25 & 0.36 & 0.23 & 0.41 & 0.24 & 0.38 & 0.0816 & 1.58 \\
RFN20 & 0.20 & 0.15 & 0.10 & 0.17 & 1.15 & 0.93 & 0.14 & 0.51 & 0.40 & 0.44 & 0.7813 & 1.11 \\
Bacteroides & 0.20 & 0.17 & 0.03 & 0.58 & 0.43 & 0.28 & 0.27 & 0.22 & 0.23 & 0.31 & 0.6107 & 1.34 \\
Dialister & 0.17 & 0.03 & 0.75 & 0.00 & 0.40 & 0.00 & 0.00 & 0.00 & 0.33 & 0.01 & 0.0491 & 0.02 \\
Clostridium & 0.15 & 0.36 & 0.06 & 0.05 & 2.04 & 0.63 & 0.31 & 0.78 & 0.64 & 0.45 & 0.5288 & 0.70 \\
Desulfovibrio & 0.13 & 0.29 & 0.21 & 0.34 & 0.11 & 0.27 & 0.16 & 0.34 & 0.15 & 0.31 & 0.0013 & 2.04 \\
Pyramidobacter & 0.13 & 0.24 & 0.12 & 0.24 & 0.05 & 0.12 & 0.09 & 0.22 & 0.10 & 0.20 & 0.0045 & 2.10 \\
Moryella & 0.12 & 0.70 & 0.09 & 0.48 & 0.32 & 0.51 & 0.49 & 0.88 & 0.25 & 0.64 & 0.0212 & 2.54 \\
Selenomonas & 0.12 & 1.29 & 0.33 & 0.98 & 0.55 & 0.68 & 1.13 & 0.34 & 0.53 & 0.82 & 0.2378 & 1.55 \\
Catenibacterium & 0.09 & 0.00 & 0.00 & 0.01 & 0.07 & 0.02 & 0.00 & 0.01 & 0.04 & 0.01 & 0.1282 & 0.24 \\
Dorea & 0.09 & 0.02 & 0.14 & 0.02 & 0.04 & 0.01 & 0.01 & 0.04 & 0.07 & 0.02 & 0.0671 & 0.31 \\
Archaea & & & & & & & & & & & \\
Euryarchaeota & 1.18 & 2.31 & 0.77 & 4.98 & 1.20 & 3.42 & 2.98 & 4.47 & 1.53 & 3.79 & 0.0266 & 2.48 \\
Crenarchaeota & 0.01 & 0.01 & 0.00 & 0.04 & 0.00 & 0.04 & 0.02 & 0.01 & 0.01 & 0.02 & 0.2152 & 3.00 \\
Methanobacteria & 1.13 & 2.20 & 0.73 & 4.83 & 1.15 & 3.25 & 2.84 & 4.27 & & & \\
Methanococci & 0 & 0 & 0 & 0 & 0 & 0 & 0 & 0 & & &
\end{tabular}

(Additional file 3: Table S3), the relative abundance of all genes directly involved in methanogenesis was similar (mean 2.82, SD 0.27, times greater in high emitting animals). The relative abundances of the genes encoding interacting enzymes, coenzyme $\mathrm{F}_{420}$ hydrogenase (EC:1.12.98.1) and heterodisulfide reductase (EC:1.8.98.1), were similar to each other and to the genes of the main pathway (mean 2.77, SD 0.20, times greater in high emitting animals). Phosphoserine phosphatase (EC:3.1.3.3) was similarly more abundant in high emitters $(2.72 \times, P=0.040)$. Most uncorrected $P$ values associated with the high-low differences were $<0.05$, many being much lower (Additional file 4: Table S4).

(b) Genes directly involved in acetogenesis. Acetogenesis by the Ljungdahl-Wood reductive acetogenesis pathway can be divided into three parts [32]. The first part involves the synthesis of 5-methyl-tetrahydrofolate. The first enzyme is an NADP-dependent formate dehydrogenase (EC:1.2.1.43). Only two of the 5.3 million gene assignations mapped to this gene (Additional file 3: Table S3). Enzymes that involve the metabolism of formate via tetrahydrofolate (THF) intermediates to 5-methylTHF, including 10-formyl-THF synthetase (EC:6.3.4.3), 10-formyl-THF deformylase (EC:3.5.1.10), 10-formyl-THF cyclohydrolase (EC:3.5.4.9), 5-formyltetrahydrofolate cycloligase (EC:6.3.3.2), 5,10-methylene-THF dehydrogenase
(EC:1.5.1.5) and 5,10-methylene tetrahydrofolate reductase (EC:1.5.1.20 (NADPH)) were present at higher abundance, but none differed significantly between the high and low emitters (Additional file 4: Table S4). Reduction of $\mathrm{CO}_{2}$ to $\mathrm{CO}$ initiates the capture of $\mathrm{CO}_{2}$ [32]; carbon monoxide dehydrogenase iron sulfur subunit (K00196) was $2.22 \times$ more abundant in high emitters $(P=0.017)$ and $C O$ dehydrogenase maturation factor (K07321) $2.57 \times$ more abundant, though not significantly so $(P=0.180)$. The carbon monoxide dehydrogenase/acetyl-CoA synthase reaction catalysed by EC:2.3.1.69 [33] is the only enzyme that is thought to be unique to reductive acetogenesis [34]; none of the reads was assigned to this gene, despite its having been found in several ruminal bacteria [34].

(c) Genes associated with methanotrophy, methane monooxygenase (EC:1.14.18.3) and methanol dehydrogenase (EC:1.1.2.7), were not identified in the dataset.

(d) The KEGG data were assembled into genes with an abundance of $>0.01 \%$ and that differed between high- and low-emitters by uncorrected $P<0.05$ (Additional file 4: Table S4). The genes directly involved in methanogenesis ((a) above) feature significantly among the increased gene abundances in this Table. Among the 125 genes thus identified, several hypothetical proteins appear. Among the genes whose abundance was higher in high emitters (and not appearing under (a)) were genes associated with 
Table 3 Partial least squares estimates of KEGG genes and diet effects and the variation in methane emissions. Partial least squares estimates of KEGG genes and diet effects in an analysis where the partial least squares factors ${ }^{\mathrm{a}}$ explaining $87.6 \%$ of the variation of model effects and $87.9 \%$ of the variation in methane emissions

\begin{tabular}{|c|c|c|c|}
\hline KEGG ID/Diet & Description & ${ }^{b}$ Estimate & ${ }^{\mathrm{q} V I P}$ \\
\hline K06001 & Tryptophan synthase beta chain [EC:4.2.1.20] & 0.13310 & 1.233 \\
\hline Diet conc & Concentrate based diet & -0.14695 & 1.204 \\
\hline Diet mixed & Mixed forage-concentrate diet & 0.14695 & 1.204 \\
\hline K02118 & V/A-type $\mathrm{H}^{+}$-transporting ATPase subunit B [EC:3.6.3.14] & 0.07984 & 1.151 \\
\hline K02117 & V/A-type $\mathrm{H}^{+}$-transporting ATPase subunit A [EC:3.6.3.14] & 0.08564 & 1.133 \\
\hline K00638 & Chloramphenicol O-acetyltransferase [EC:2.3.1.28] & 0.06182 & 1.082 \\
\hline K00200 & Formylmethanofuran dehydrogenase subunit A [EC:1.2.99.5] & 0.06042 & 1.070 \\
\hline K03531 & Fell division protein FtsZ & 0.07526 & 1.065 \\
\hline K00201 & Formylmethanofuran dehydrogenase subunit B [EC:1.2.99.5] & 0.04859 & 1.049 \\
\hline K00399 & Methyl-coenzyme $M$ reductase alpha subunit [EC:2.8.4.1] & 0.03843 & 1.021 \\
\hline K00123 & Formate dehydrogenase, alpha subunit [EC:1.2.1.2] & 0.03417 & 1.013 \\
\hline K03388 & Heterodisulfide reductase subunit A [EC:1.8.98.1] & 0.02734 & 0.997 \\
\hline K14126 & $\mathrm{F}_{420}$-non-reducing hydrogenase subunit A [EC:1.12.99.-] & 0.00384 & 0.933 \\
\hline K01079 & Phosphoserine phosphatase [EC:3.1.3.3] & 0.03424 & 0.932 \\
\hline K00401 & Methyl-coenzyme M reductase beta subunit [EC:2.8.4.1] & 0.00484 & 0.909 \\
\hline K00527 & Ribonucleoside-triphosphate reductase [EC:1.17.4.2] & 0.03449 & 0.898 \\
\hline K02337 & DNA polymerase III subunit alpha [EC:2.7.7.7] & -0.05338 & 0.886 \\
\hline K02837 & Peptide chain release factor RF-3 & 0.00883 & 0.852 \\
\hline K01893 & Asparaginyl-tRNA synthetase [EC:6.1.1.22] & -0.06673 & 0.812 \\
\hline K00925 & Acetate kinase [EC:2.7.2.1] & -0.00903 & 0.812 \\
\hline K00656 & Formate C-acetyltransferase [EC:2.3.1.54] & -0.00834 & 0.787 \\
\hline K02948 & Small subunit ribosomal protein $\mathrm{S} 11$ & -0.00400 & 0.734 \\
\hline
\end{tabular}

Genes in bold type are archaeal genes associated with methane production

${ }^{a}$ Two factors were significant in the partial least squares analysis

${ }^{b}$ Estimates based on predictors and responses to be centred and scaled to have mean 0 and standard deviation 1

'Variable Importance for Projection (VIP) statistic of Wold [67], which summarizes the contribution of a variable marker to the model

methane, hydrogen or archaeal energy metabolism: a $\mathrm{H}_{2}$-dependent 5,10-methenyltetrahydromethanopterin hydrogenase (EC:1.12.98.2) (4.31×); cobalt/nickel transport system permease protein (K02007; 2.88×) would help provide $\mathrm{Ni}$ to the $\mathrm{Ni}$-dependent methyl reductases, hydrogenases and coenzyme $\mathrm{F}_{430}$ involved in methanogenesis; hydrogenase nickel incorporation protein HypB was $2.48 \times$ more abundant in high emitters $(P=0.004)$. Genes encoding subunits of $\mathrm{V}$-type $\mathrm{H}^{+}$-transporting ATPase (EC:3.6.3.14) were 2.18-2.87× more abundant in high emitters. Subunits of pyruvate ferredoxin oxidoreductase (EC:1.2.7.1) were on average $2.96 \times$ more abundant in high emitters (Additional file 5: Table S5).

Among other genes associated with hydrogenase activity, $\mathrm{F}_{420}$-non-reducing hydrogenase (EC:1.12.99.-) subunits A, $\mathrm{D}$ and $\mathrm{G}$ were $2.64 \times, 3.58 \times$ and $3.01 \times$ more abundant in high emitters. Likewise, hydrogenase expression/formation protein (K07388) was $2.52 \times$ more abundant, along with hydrogenase maturation protein HypF 2.54x; hydrogenase expression/formation protein HypC 5.17x, HypD 2.66x and HypE $2.94 \times$. Energy-converting hydrogenase A subunits B 4.15×, C 3.75×, E 2.53×, G 3.00×, H 2.52×; J 2.65×, M 2.32×, N 3.02×, O 2.11×, P 2.39x, Q 3.31× and R 3.67× and were more abundant in high emitters as were energyconverting hydrogenase B subunits A 4.12×, F 3.33×, H $3.60 \times, \mathrm{K} 2.67 \times, \mathrm{L} 2.85 \times, \mathrm{M} 2.53 \times$ and N 2.59×.

Two genes of the pentose phosphate pathway tended to be less abundant, glucose-6-phosphate isomerase (EC:5.3.1.9, 0.615×, $P=0.054$ ) and transketolase (EC:2.2.1.1, $0.692 \times, P=0.104)$. Transaldolase (EC:2.2.1.2, 0.389×, $P=0.279)$ was numerically less abundant, but other enzymes of this pathway were either not identified or not different (EC:3.1.1.17, 1.1.1.49, 3.1.1.17, .1.1.1,44, 5.1.3.1; Additional file 4: Table S4).

Other genes that were of higher abundance in high emitters included transcription initiation factor TFIIB (K03124, 2.63×, $P=0.009$ ), which is archaeal, and transcription initiation factor TFIID TATA-box-binding 


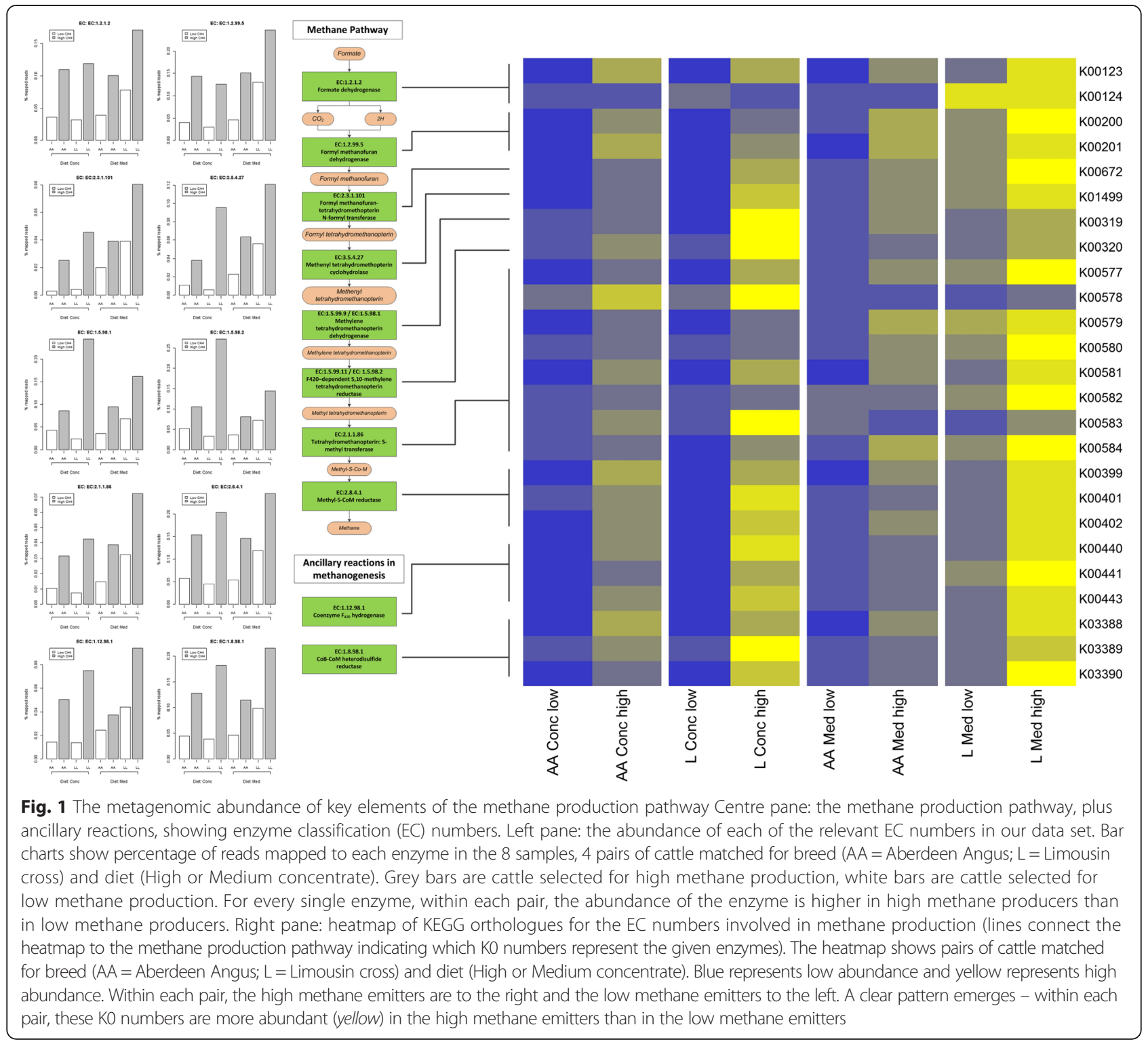

protein (K03120; 4.31×, $P=0.027$ ), which is present in all domains. The enzymes NADH dehydrogenase (EC:1.6.99.3, $2.60 \times, P=0.018$ ) and (R)-2-hydroxyacid dehydrogenase (EC:1.1.1.272, 4.09×, $P=0.024$ ) were also more abundant in high emitters.

Genes that were less abundant in high emitters included electron transport complex proteins RnfC (K03615, 0.357×, $P=0.010)$ and RnfD (K03614, 0.550×, $P=0.027$ ), and $\mathrm{F}-$ type $\mathrm{H}^{+}$-transporting ATPase subunit a (EC:3.6.3.14, $0.620 \times, P=0.028$ ) (Additional file 4: Table S4). Acetate kinase was lower (EC:2.7.2.1, 0.559×, $P=0.024)$ and there were trends for the related enzymes, phosphate acetyl transferase (EC:2.7.2.1, acetyl-CoA:phosphate acetyltransferase, $0.596 \times, P=0.066)$ and pyruvate kinase (EC:2.7.1.40, 0.366 $\times, P=0.074$ ) also to be lower
(Additional file 4: Table S4). Others included saccharopine dehydrogenase $\left(\mathrm{NAD}^{+}\right.$, L-lysine forming) (EC:1.5.1.7, $0.549 \times, P=0.039)$ and replicative DNA helicase (EC:3.6.4.12, $0.555 \times, P=0.015]$.

The positions of several genes on the KEGG metabolic pathways involved in and related to methanogenesis are highlighted in Additional file 6: Figure S1.

\section{De novo assembly and gene prediction}

Metagenomic data were assembled de novo, and predicted genes and proteins were annotated using Pfam [35]. Across all eight samples, there were $1,500,390$ predicted proteins, of which a Pfam domain could be assigned to 729,736 (48.6\%). Of those, 97,214 were DUF domains - "domain of unknown function". Therefore a domain could not be 
Table 4 Counts of predicted rumen metagenomic proteins and their KO group. Summary of 2774 predicted proteins from the 8 metagenomic rumen samples. KEGG ID is the predicted KO group. Columns show the number of full length candidates within each K0 group, the number which have $100 \%$ identical matches in NR, the number showing $100 \%$ conservation with a protein in NR, the number with a $90 \%$ identical match, and the number showing at least $90 \%$ conservation with a protein in NR

\begin{tabular}{|c|c|c|c|c|c|c|}
\hline KEGG ID & Description & $\begin{array}{l}\text { \# full length } \\
\text { candidates }\end{array}$ & $\begin{array}{l}\text { \# } 100 \% \\
\text { identical in NR }\end{array}$ & $\begin{array}{l}\text { \# } 100 \% \\
\text { conserved in NR }\end{array}$ & $\begin{array}{l}\text { \# } 90 \% \\
\text { identical NR }\end{array}$ & $\begin{array}{l}\text { \# } 90 \% \\
\text { conserved in NR }\end{array}$ \\
\hline K06001 & $\begin{array}{l}\text { Tryptophan synthase beta } \\
\text { chain [EC:4.2.1.20] }\end{array}$ & 194 & 1 & 1 & 32 & 78 \\
\hline K02118 & $\begin{array}{l}\text { V/A-type } \mathrm{H}^{+} \text {-transporting ATPase } \\
\text { subunit B [EC:3.6.3.14] }\end{array}$ & 337 & 2 & 4 & 65 & 169 \\
\hline K02117 & $\begin{array}{l}\text { V/A-type } \mathrm{H}^{+} \text {-transporting ATPase } \\
\text { subunit A [EC:3.6.3.14] }\end{array}$ & 105 & & & & 21 \\
\hline K00638 & $\begin{array}{l}\text { Chloramphenicol O-acetyltransferase } \\
\text { [EC:2.3.1.28] }\end{array}$ & 76 & 3 & 3 & 7 & 25 \\
\hline K00200 & $\begin{array}{l}\text { Formylmethanofuran dehydrogenase } \\
\text { subunit A [EC:1.2.99.5] }\end{array}$ & 57 & & & 2 & 8 \\
\hline K03531 & Cell division protein FtsZ & 167 & & & 3 & 4 \\
\hline K00201 & $\begin{array}{l}\text { Formylmethanofuran dehydrogenase } \\
\text { subunit B [EC:1.2.99.5] }\end{array}$ & 20 & & & 3 & 7 \\
\hline K00399 & $\begin{array}{l}\text { Methyl-coenzyme M reductase alpha } \\
\text { subunit [EC:2.8.4.1] }\end{array}$ & 1 & & & 1 & 1 \\
\hline K00123 & $\begin{array}{l}\text { Formate dehydrogenase, alpha } \\
\text { subunit }[E C: 1.2 .1 .2]\end{array}$ & 3 & & & & 1 \\
\hline K03388 & $\begin{array}{l}\text { Heterodisulfide reductase } \\
\text { subunit A [EC:1.8.98.1] }\end{array}$ & 352 & 1 & 1 & 26 & 75 \\
\hline K14126 & $\begin{array}{l}\mathrm{F}_{420} \text {-non-reducing hydrogenase } \\
\text { subunit A [EC:1.12.99.-] }\end{array}$ & 6 & & & 1 & 4 \\
\hline K01079 & Phosphoserine phosphatase [EC:3.1.3.3] & 0 & 0 & 0 & 0 & 0 \\
\hline K00401 & $\begin{array}{l}\text { Methyl-coenzyme M reductase beta } \\
\text { subunit [EC:2.8.4.1] }\end{array}$ & 2 & & & & \\
\hline K00527 & $\begin{array}{l}\text { Ribonucleoside-triphosphate } \\
\text { reductase [EC:1.17.4.2] }\end{array}$ & 120 & & & 24 & 57 \\
\hline K02337 & $\begin{array}{l}\text { DNA polymerase III subunit } \\
\text { alpha [EC:2.7.7.7] }\end{array}$ & 108 & & & 5 & 12 \\
\hline K02837 & Peptide chain release factor RF-3 & 569 & 2 & 5 & 103 & 271 \\
\hline K01893 & Asparaginyl-tRNA synthetase [EC:6.1.1.22] & 437 & & 3 & 54 & 155 \\
\hline K00925 & Acetate kinase [EC:2.7.2.1] & 132 & 1 & 1 & 23 & 38 \\
\hline K00656 & Formate C-acetyltransferase $[\mathrm{EC}: 2.3 .1 .54]$ & 101 & & & 18 & 54 \\
\hline K02948 & Small subunit ribosomal protein S11 & 178 & 6 & 16 & 49 & 57 \\
\hline
\end{tabular}

assigned to over half of the predicted proteins, and a putative function to almost $58 \%$.

Of the 20 KEGG orthologues in Table 3 significantly associated with methane emissions, 2774 putative full length members were discovered in our data set (Table 4). These were searched against NR using BLAST [36]. Of the 2774 predicted proteins, only $16(0.6 \%)$ gave an exact match in NR, and only 34 (1.2\%) showed $100 \%$ amino acid conservation. Furthermore, only 407 (14.7 \%) showed $90 \%$ identity with a protein in NR and only 990 (35.7 \%) showed $90 \%$ amino acid conservation.

Predicted proteins, and their domains, are available as a Meta4 database [37] at http://www.ark-genomics.org/ tools/meta4

\section{Discussion}

In the present study, ruminal digesta samples from beef cattle with extreme high and low emissions, identified from an earlier 72-animal study [29, 30], were used to pinpoint key differences in their microbial communities and metagenomes that might help explain the methane phenotype and thereby offer new avenues to explore means of mitigation. Methane emissions correlated with archaeal abundance in the rumen based on 16S rRNA genes and the abundance of other archaeal genes, particularly those involved directly or indirectly with methanogenesis, was greater in high methane emitters. Differences in other members of the rumen microbial community pointed for the first time to a role of Succinovibrionaceae in low 
methane emissions in ruminants; bacterial gene abundances were consistent with this interpretation. The results of protein mapping analysis from metagenomic sequences highlight that the majority of genes and proteins had no homologues in public databases and that there are many differences between high- and low-emitting beef cattle that could be useful for exploitation.

Previous qPCR analysis of the whole 72-animal experimental group suggested a correlation, albeit rather weak, between archaeal abundance and methane emissions from individual animals [30]. It might be argued that the extreme animals, as investigated here, might give a better impression of what opportunities might be available for modulating methane emissions. The differences in methane emissions, expressed per kg DM intake, between selected low and high emitters were substantial $(1.88 \times)$, thus the causes of these differences might be more easily identified. Post-mortem digesta sampling was used here, following our previous discovery that the abundance of archaea relative to bacteria was similar in live cattle when leaving the respiration chambers and when digesta were sampled at slaughter ca. two weeks later [30].

The rumen microbial community comprises mainly ciliate protozoa, anaerobic bacteria and fungi and archaea. Methanogenesis in the rumen occurs predominantly by the hydrogenotrophic route, i.e. $4 \mathrm{H}_{2}+\mathrm{CO}_{2}=\mathrm{CH}_{4}+2 \mathrm{H}_{2} \mathrm{O}$ $[5,6]$. The first three microbial groups provide the $\mathrm{H}_{2}$, and the archaea carry out methanogenesis. It therefore seems intuitive that methane emissions should correspond to some extent with archaeal abundance in the rumen, from where $87 \%$ of enteric emissions originate in the digestive tract [38]. Yet, except for our previous studies [30], proof of such a correlation has proved elusive $[6,24,26-28,39]$. The higher proportion of archaea in high emitters in the present study was similar whether calculated from qPCR or deep sequencing reads of $16 \mathrm{~S}$ rRNA genes. The large difference between high and low emitters may explain why differences in gene abundance may become more evident. Shi et al. [24] found differences in the ruminal transcriptome but not the metagenome that correlated with sheep emitting different amounts of methane. We would submit that there are strong theoretical reasons why methane emissions should be proportional to the abundance of archaea present in the rumen of individual animals rather than transcript abundances. The biomass yield of the archaea must normally be directly proportional to the methane produced, since, with minor possible exceptions such as alcohol utilization [4], methanogenesis is the only mechanism of ATP synthesis available to the archaea. Furthermore, the cytochrome-containing genera [40] have not been reported in the rumen [41], so the molar growth yields of the different genera that are found in the rumen are likely to be similar. Uncoupling between methanogenesis and
ATP synthesis $[42,43]$ could explain a lack of correspondence between archaeal abundance and methane emissions. Such uncoupling occurs at high $\mathrm{H}_{2}$ partial pressures in some archaea [44], but is not known in ruminal archaea as far as we are aware. Furthermore, the partial pressure of $\mathrm{H}_{2}$ in the rumen is always low [45]. Several different archaeal genera have been found in the rumen in different species of ruminant in different geographical locations [41]. As found here by examining 16S rRNA reads from the metagenomes, Methanobrevibacter usually predominates [41, 46, 47]. The abundance of Methanobrevibacter varied from 1.9 to $11.0 \%$ compared to bacterial abundance.

A greater abundance of archaea in high emitters would be expected to be a response to rather than the root cause of the difference in emissions, unless major differences in $\mathrm{H}_{2}$ emissions were found, which was not the case [29]. The availability of $\mathrm{H}_{2}$ limits the rate of ruminal methanogenesis under some circumstances [45]. Thus, methane emissions might be expected to be at least partly dependent on the abundance of $\mathrm{H}_{2}$-producing microorganisms. Ciliate protozoa are major producers of $\mathrm{H}_{2}$, produced by mitochondrion-like organelles known as hydrogenosomes [48]. They were generally more abundant in high emitters, but the differences were not statistically significant. Kittelmann et al. [49] also did not find links between protozoa and methane. The bacterial Firmicutes phylum, of which the main ruminal members are Clostridium Clusters IV and XIV, would contain more $\mathrm{H}_{2}$ producers, particularly Clostridium Cluster IV in which the main ruminal community members are the highly cellulolytic Ruminococcus and several Eubacterium spp. [50, 51], than the Bacteroidetes, which generally are net $\mathrm{H}_{2}$ utilisers [51]. Trends in this direction occurred, but as observed with the whole animal group $[29,30]$ no statistically significant differences in their abundance were observed. Stronger associations between methane emissions and abundance of $\mathrm{H}_{2}$-producing bacteria in sheep have been reported by Kittelmann et al. [49], who distinguished three 'ruminotypes'. The high methane emitters generally had a greater community of $\mathrm{H}_{2}$-producing bacteria than low emitters.

Highly significant differences were observed in the abundances of some bacterial taxa based on 16S rRNA sequences extracted from the metagenome. Proteobacteria were 4-fold more abundant in low emitters. The predominant Proteobacteria belonged to the family Succinivibrionaceae. This observation has a curious correspondence with the abundance of Succinivibrionaceae in the digestive tract of the Tammar wallaby (9\% of total bacteria) [52], which was considered to be the main reason why the Tammar wallaby produces one quarter of the methane emissions of cattle [52, 53]. Succinivibrionaceae were just as abundant in the low-emission beef cattle investigated here as in the wallaby. These bacteria 
produce succinate as a main fermentation product, thus trapping metabolic hydrogen rather than releasing it as $\mathrm{H}_{2}$. It may be that the main Succinivibrionaceae species are different in the two animal hosts; indeed, Pope et al. [52] did not find any of the major wallaby species of Succinivibrionaceae in cattle. Nonetheless, the finding that Succinivibrionaceae were much more numerous in low-emitting cows is consistent with the wallaby observations and offers a possible strategy for lower methane emissions from ruminant livestock.

Other significant differences in bacteria may not be explained directly in terms of methane emissions, but possible related causes of the differences are of interest. Desulfovibrio, like archaea, are $\mathrm{H}_{2}$ utilisers, using $\mathrm{H}_{2}$ to reduce sulphate to sulphide $[54,55]$; their 2 -fold higher abundance in high emitters might therefore be linked with a greater availability of $\mathrm{H}_{2}$. Megasphaera is a genus associated with adaptation of the ruminal community to low $\mathrm{pH}[56,57]$. Their greater abundance in low emitters could be indicative of a less stable $\mathrm{pH}$ in these animals. (Ruminal pH was not measured here, because such measurements made post mortem have limited or no value). Dialister, from the phylum Firmicutes, family Selenomonadales, which also were much more abundant in low emitters, might fall into a similar category based on their metabolic properties [58]. Ruminal methanogenesis is highly sensitive to low $\mathrm{pH}[59,60]$, thus the cause of the greater abundance of these bacterial genera in low emitters may be consistent with a low-pH inhibition of archaea in these animals. Two unrelated genera that were more abundant in high emitters were Mogibacterium and Pyramidobacter, both of which are asaccharolytic [61, 62]. Why such a characteristic should enrich for bacteria with this type of metabolism in high methane emitters is unclear. Quinella spp., which were found to be more abundant in low-emitting sheep [49], were not resolved in our taxonomic analysis. However, at the family level, the Veillonellaceae, of which Quinella is a member, were considerably more numerous in the lowemitting cattle.

Relatively low values of Shannon diversity reflected the low taxonomic richness and dominance of genera such as Prevotella and Butyrivibrio within the bacteria and Methanobrevibacter within the archaea. The lack of any significant difference in diversity statistics between the high and low emitting animals indicated that the generic taxonomic composition of the microbiome was not altered as a result of the breed, diet or methane emission profile. However, it is likely that these measurements of diversity were not sensitive enough to detect differences in microbiome populations associated with methane profiles. Correspondence analysis carried out on larger sample numbers [49] or detailed analyses such as the quantitative PCR carried out here, was required to reveal more subtle changes in the key microbial species involved in methanogenesis.

Bacterial gene abundances that differed in low and high emitters included several involved in acetate formation and pyruvate metabolism. Acetate kinase (EC:2.7.2.1), which catalyses the conversion of acetyl phosphate to acetate with the formation of ATP, was $0.56 \times$ as abundant in high emitters. Phosphotransacetylase (EC:2.3.1.8) forms acetyl phosphate from acetyl $\mathrm{CoA}$; its abundance was similarly lower $(0.60 \times)$ in high emitters. A possible alternative route for acetate formation, acetate thiokinase (EC:6.2.1.1), was unchanged. Pyruvate ferredoxin oxidoreductase (EC:1.2.7.1), which forms acetyl CoA from pyruvate while reducing ferredoxin, showed a higher abundance of its $\alpha, \beta, \gamma$ an $\delta$ subunits by 2.9, 2.7, 3.2 and $3.2 \times$, respectively, in high emitters. In contrast, pyruvate formate lyase, an alternative route of acetyl CoA formation from pyruvate, had much lower abundance $(0.32 \times)$ in high emitters. Thus, the ruminal microbiota in high methane emitters metabolised pyruvate differently to low emitters, favouring the pyruvate formate lyase - acetate kinase route. Perhaps significantly, this is the route by which pyruvate is converted to acetate used by Succinivibrionaceae isolate WG-1 from the Tammar wallaby [52]. Two genes of the pentose phosphate pathway characteristic of the wallaby species WG-1 [52] and WG-2 [53] also tended to be more abundant in low emitters.

It was notable that genes which catalyse methane oxidation [63] were absent, suggesting that significant methane oxidation does not occur in beef cattle. Reverse methanogenesis remains a possibility, however [64]. Although some genes associated with reductive acetogenesis, such as carbon monoxide dehydrogenase iron sulfur subunit and $\mathrm{CO}$ dehydrogenase maturation factor, were more abundant in high emitters, the only enzyme that is thought to be unique to reductive acetogenesis, carbon monoxide dehydrogenase/acetyl-CoA synthase (EC:2.3.1.69) [33, 34] was not present, despite its having been found in several ruminal bacteria [34].

Multiple comparison analysis was not carried out here, for simple reasons. In Table 2, for example, 16 out of 52 $P$ values are significant at $P<0.05$, which clearly exceeds the false positive rate. As this was an exploratory study, rather than one which aimed to test specific hypotheses, we considered that a multiple testing adjustment of individual $P$ values, such as a Bonferroni correction, would severely inflate the false negative rate. We therefore preferred to present unadjusted $P$ values, leaving it to the reader to bear in mind that a few (2-3) of them can be expected to be false positives, though most will not.

Among the aims of the type of methane research described here are to find proxies for estimating methane emissions - the respiration chambers used in the present experiments are expensive and laborious, 
unsuited to large numbers of animals - and to identify targets for interventions to lower methane emissions. Here, comparisons of metagenomic profiles identified differences that characterise high- and low-emitting animals. Table 3 describes the cumulative contribution of a group of genes on methane emissions, considering the correlations among gene effects. Thereby, the effect of each gene is estimated independently from those of all other genes in the model. The order of importance of the genes may reflect therefore more the independent regulatory effects of each gene on methane emissions. Thus, there are several possible strategies for identifying proxies and targets.

Our results demonstrate that the rumen is still a hugely unexplored environment containing many novel enzymes, which could be of significant interest to the agricultural and biotechnology markets. From just 8 samples and a little under $88 \mathrm{~Gb}$ of sequencing data, we were able to predict over 1.5 million proteins, the majority of which we were unable to assign function to. Predicting the function of proteins such as these (those with no hits in public databases) will be a major challenges facing biologists in the next decade. Of the proteins we could assign some function to, the vast majority were novel, with over $99 \%$ of them having no exact matches within NR, and the majority showing conservation levels below $90 \%$. We can predict their function through homology to enzymes and proteins of known function; however, undoubtedly they will differ in their ability to catalyse reactions, and some may be more efficient at their task, which would be of profound interest to a range of researchers and companies in biotechnology. By releasing all 1.5 million proteins, with predicted domains, as a Meta4 database, we allow researcher to explore a dataset of huge importance and impact.

\section{Conclusion}

In conclusion, the results presented here demonstrate that the abundance of archaea and their constituent genes corresponds strongly with methane emissions by the host animal. The gene abundances can now be used individually or collectively as proxies for methane emissions in genetic screening studies. The discovery that pyruvate and acetate metabolism and the numbers of Succinivibrionaceae differ between low and high emitters may bring insight into how metabolic pathways and the microbial community might be manipulated to lower methane emissions and thus lessen the environmental footprint of ruminant livestock production.

\section{Methods}

Animals, experimental design and diets

This study was conducted at the Beef and Sheep Research Centre of SRUC (6 miles south of Edinburgh,
UK) in summer 2011. The experiment was approved by the Animal Experiment Committee of SRUC and was conducted in accordance with the requirements of the UK Animals (Scientific Procedures) Act 1986. Full details of the methodology of animal experimentation have been provided previously [29, 30]. Only an outline is given here.

Thirty-six Aberdeen Angus and 36 Limousin cross bred steers received one of two diets, one mainly concentratebased and the other a forage-concentrate-based diet, with forage:concentrate ratios (DM basis) of 8:92 and 48:52, respectively. The composition of the diets is given in Additional file 7: Table S6. Feed samples were analysed for DM, ash, CP, ADF and NDF according to standard methods [65]. Gross energy of feeds was performed on dried samples by adiabatic bomb calorimetry. All cattle came from the same breeding herd population and were kept in the identical farm environment throughout their lifetimes.

Eighteen animals of each breed received each diet. Methane emissions were measured individually for $48 \mathrm{~h}$ in respiration chambers. Samples of ruminal digesta were recovered at slaughter up to 2 weeks later. The highest and lowest emitter, expressed as g methane per $\mathrm{kg}$ DM intake, were identified from each of the breed/diet combinations and the stored DNA was subjected to qPCR of $16 \mathrm{~S}$ rRNA genes and to deep sequencing.

\section{qPCR of $16 \mathrm{~S}$ and $18 \mathrm{~S}$ rRNA genes}

Sample storage and DNA extraction were carried out using methods described and authenticated in previous studies, as described by Rooke et al. [29]. Primers used for amplification of $16 \mathrm{~S}$ and $18 \mathrm{~S}$ rRNA genes, amplification protocols, calibration and calculation of gene abundance were also the same as those reported by Rooke et al. [29].

\section{Deep sequencing and KEGG analysis}

Illumina TruSeq libraries were prepared from genomic DNA and sequenced on an Illumina HiSeq 2500 instrument by Edinburgh Genomics. 100-bp paired-end reads were generated, resulting in between 8.6 and $14.5 \mathrm{~Gb}$ per sample (between 43.4 and 72.7 million paired reads).

For 16S rRNA gene analysis, the genomic reads were aligned to the GREENGENES database [66] using Novoalign (www.novocraft.com). Parameters were adjusted such that all hits were reported that were equal in quality to the best hit for each read, and allowing up to a $10 \%$ mismatch across the fragment. Taxa were assigned to each read as follows. Where a read hit a single entry in the GREENGENES database, the full taxonomy for that hit was taken. Where a read hit multiple entries in the GREENGENES database, the lowest common taxon was taken. The number of reads 
that matched at each of Kingdom, Phylum and Genus were counted, normalised to the total number of hits and expressed as a percentage.

The genus abundance table, based on counts, was used to generate diversity statistics for the microbiome in each sample. Shannon index [67] was used as a measure of richness and evenness and Chaol index [68] to calculate the estimated total number of prokaryotic genera.

For functional analysis, a similar approach was taken. The genomic reads were aligned to the KEGG genes database using the same parameters, read counts for KEGG orthologues summed and normalised to the total number of hits. We first aligned reads directly to KEGG genes allowing for up to a $10 \%$ mismatch. The KEGG Orthologue groups (KO) of all hits that were equal to the best hit were examined. If we were unable to resolve the read to a single $\mathrm{KO}$, the read was ignored; otherwise, the read was assigned to the unique $\mathrm{KO}$.

\section{Calculations and statistical analysis}

Microbial 16S rRNA abundances were compared using paired $t$-tests. Comparisons of gene abundances were carried out as follows. Firstly, a generalized linear model analysis (GLM, Version 9.1 for Windows, SAS Institute Inc., Cary, NC, USA) was performed, fitting diet effects $(P<0.05)$ and one KEGG gene each time. Breed showed non-significant effects $(P>0.1)$ on methane emissions per $\mathrm{kg}$ DM intake and therefore was not fitted in the model. Secondly, a partial least squares analysis (PLS, Version 9.1 for Windows, SAS Institute Inc., Cary, NC, USA) was carried out fitting all KEGG genes identified in the GLM analysis to have $P<0.1$ (including diet effects) in order to account for multiple testing and the correlations among all these model effects. Model effects with a variable importance for projection (VIP) criteria [69] of $<0.8$ were removed from the model because Wold [69] indicates that those effects contribute little to the prediction. No further PLS analyses were carried out even when a few genes moved below VIP values of 0.8 .

\section{Metagenomic assembly and gene prediction}

Each sample was assembled de novo using MetaVelvet [70] and a kmer of 51. From the resulting scaffolds, microbial genes were predicted using Prokka [71], and compared to Pfam [35] using HMMER [72]. All protein predictions and annotations were uploaded to a Meta4 database [37]. We applied a $P$-value cut-off of 0.01 to the resulting domain predictions and counted the number of protein predictions which were assigned domains.

We then searched for members of the 20 KEGG orthologous groups from Table 3 in our dataset. Specifically, for each of the 20 KEGG orthologous groups in Table 3, we searched for predicted proteins that had a similar domain structure and which were greater than or equal to the length of the smallest protein in the group. These were then compared to the NR database using BLAST [36].

\section{Availability of supporting data}

Predicted proteins, and their domains, are available as a Meta4 database [37] at http://www.ark-genomics.org/ tools/meta4. Raw data are available in the European Nucleotide Archive under accession PRJEB10338.

\section{Additional files}

Additional file 1: Table S1. Analysis of reads of $16 \mathrm{~S}$ rRNA assigned to
Proteobacteria (DOCX $15 \mathrm{~kb}$ )

Additional file 2: Table S2. Diversity statistics based on microbial genus abundance in high and low methane emitting cattle. (DOCX $12 \mathrm{~kb}$ )

Additional file 3: Table S3. KEGG dataset in order of average gene abundance. (XLSX $1400 \mathrm{~kb}$ )

Additional file 4: Table S4. KEGG dataset in order of the ratio of gene abundance, high:low emitters. (XLSX $443 \mathrm{~kb}$ )

Additional file 5: Table S5. Gene abundance of genes of pyruvate metabolism in low and high methane steers. (DOCX 14 kb)

Additional file 6: Figure S1. KEGG pathways associated with methane metabolism. Highlighted EC gene numbers are those genes that differed significantly between high and low emitting cattle. Red - genes that had higher abundance in high emitters; blue - genes that had lower abundance in high emitters. (DOC $22 \mathrm{~kb}$ )

Additional file 7: Table S6. Ingredient composition (fresh weight basis; $\mathrm{g} / \mathrm{kg}$ ) of high- concentrate and mixed forage: concentrate diets. (DOCX $11 \mathrm{~kb})$

\section{Competing interests}

The authors declare that they have no competing interests.

\section{Authors' contributions}

RJW helped design the study, interpret the results and co-authored the manuscript. JAR, CAD, JJH, DWR, AW contributed to the design of the study, carried out the experiment, helped interpret the results and co-authored the manuscript. MW helped with study design, carried out all bioinformatic analyses, helped interpret the results and co-authored the manuscript; RR designed the experiment and study, carried out genetic analysis, helped interpret the results and co-authored the manuscript. All authors read and approved the final manuscript.

\section{Acknowledgements}

The Rowett Institute of Nutrition and Health and SRUC are funded by the Rural and Environment Science and Analytical Services Division (RESAS) of the Scottish Government. The project was supported by Defra and the DA funded Agricultural Greenhouse Gas Inventory Research Platform, the Technology Strategy Board (Project No: TP 5903-40240) and the Biotechnology and Biological Sciences Research Council (BBSRC; BB/J004243/1, BB/J004235/1). Our thanks are due to the excellent support staff at the SRUC Beef and Sheep Research Centre, Edinburgh, and to Silvia Ramos Garcia for help in interrogating the data. MW and RR contributed equally to the paper and should be considered as joint last authors.

\section{Author details}

${ }^{1}$ Rowett Institute of Nutrition and Health, University of Aberdeen, Bucksburn, Aberdeen AB21 9SB, UK. ${ }^{2}$ SRUC, West Mains Road, Edinburgh EH9 3JG, UK. ${ }^{3}$ Edinburgh Genomics, The Roslin Institute and R(D)SVS, University of Edinburgh, Easter Bush, Edinburgh EH25 9RG, UK.

Received: 7 April 2015 Accepted: 8 October 2015

Published online: 23 October 2015 


\section{References}

1. Intergovernmental Panel on Climate Change. Climate change 2014. Synthesis report 2014.

2. Intergovernmental Panel on Climate Change. Guidelines for National Greenhouse Gas Inventories 2006 Vol. 4 Agriculture, Forestry and Other Land Use.

3. Cottle DJ, Nolan JV, Wiedemann SG. Ruminant enteric methane mitigation: a review. Anim Prod Sci. 2011:51:491-514.

4. Leahy SC, Kelly WJ, Altermann E, Ronimus RS, Yeoman CJ, Pacheco DM, et al. The genome sequence of the rumen methanogen Methanobrevibacter ruminantium reveals new possibilities for controlling ruminant methane emissions. PLoS One. 2010;5:e8926.

5. Martin C, Morgavi DP, Doreau M. Methane mitigation in ruminants: from microbe to the farm scale. Animal. 2010;4:351-65.

6. Morgavi DP, Forano E, Martin C, Newbold CJ. Microbial ecosystem and methanogenesis in ruminants. Animal. 2010;4:1024-36.

7. Hayes BJ, Lewin HA, Goddard ME. The future of livestock breeding: genomic selection for efficiency, reduced emissions intensity, and adaptation. Trends Genet. 2013;29:206-14

8. Hegarty RS, Goopy JP, Herd RM, McCorkell B. Cattle selected for lower residual feed intake have reduced daily methane production. J Anim Sci. 2007;85:1479-86

9. Thauer RK. Biochemistry of methanogenesis: a tribute to Marjory Stephenson 1998 Marjory Stephenson Prize Lecture. Microbiology. 1998;144:2377-406.

10. Hungate RE. Hydrogen as an intermediate in the rumen fermentation. Archiv Mikrobiol. 1967;59:158-64.

11. Poulsen M, Schwab C, Jensen BB, Engberg RM, Spang A, Canibe N, et al. Methylotrophic methanogenic Thermoplasmata implicated in reduced methane emissions from bovine rumen. Nature Commun. 2013:4:1428.

12. Ferrer M, Golyshina OV, Chernikova TN, Khachane AN, Reyes-Duarte D, Santos VAPMD, et al. Novel hydrolase diversity retrieved from a metagenome library of bovine rumen microflora. Environ Microbiol. 2005;7:1996-2010.

13. Brulc JM, Antonopoulos DA, Miller MEB, Wilson MK, Yannarell AC, Dinsdale $E A$, et al. Gene-centric metagenomics of the fiber-adherent bovine rumen microbiome reveals forage specific glycoside hydrolases. Proc Natl Acad Sci U S A. 2009;106:1948-53.

14. Hess M, Sczyrba A, Egan R, Kim T-W, Chokhawala H, Schroth G, et al. Metagenomic discovery of biomass-degrading genes and genomes from cow rumen. Science. 2011;331:463-7.

15. Bao L, Huang Q, Chang L, Sun Q, Zhou J, Lu H. Cloning and characterization of two $\beta$-glucosidase/xylosidase enzymes from yak rumen metagenome. Appl Biochem Biotechnol. 2012;166:72-86.

16. Rashamuse KJ, Visser DF, Hennessy F, Kemp J, Roux-van der Merwe MP, Badenhorst J, et al. Characterisation of two bifunctional cellulase-xylanase enzymes isolated from a bovine rumen metagenome library. Curr Microbiol. 2013:66:145-51.

17. Gruninger RJ, Gong X, Forster RJ, McAllister TA. Biochemical and kinetic characterization of the multifunctional $\beta$-glucosidase/ $\beta$-xylosidase/aarabinosidase, Bgxa1. Appl Microbiol Biotechnol. 2014;98:3003-12.

18. Liu K, Wang J, Bu D, Zhao S, McSweeney C, Yu P, et al. Isolation and biochemica characterization of two lipases from a metagenomic library of China Holstein cow rumen. Biochem Biophys Res Commun. 2009:385:605-11.

19. Privé F, Newbold CJ, Kaderbhai NN, Girdwood SG, Golyshina OV, Golyshin $\mathrm{PN}$, et al. Isolation and characterization of novel lipases/esterases from a bovine rumen metagenome. Appl Microbiol Biotechnol 2015; PMID: 25575887.

20. Singh KM, Jakhesara SJ, Koringa PG, Rank DN, Joshi CG. Metagenomic analysis of virulence-associated and antibiotic resistance genes of microbes in rumen of Indian buffalo (Bubalus bubalis). Gene. 2012;507:146-51.

21. Beloqui A, Pita M, Polaina J, Martínez-Arias A, Golyshina OV, Zumárraga M, et al. Novel polyphenol oxidase mined from a metagenome expression library of bovine rumen: biochemical properties, structural analysis, and phylogenetic relationships. J Biol Chem. 2006;281:22933-42.

22. Berg Miller ME, Yeoman CJ, Chia N, Tringe SG, Angly FE, Edwards RA, et al Phage-bacteria relationships and CRISPR elements revealed by a metagenomic survey of the rumen microbiome. Environ Microbiol. 2012;14:207-27.

23. Ciric M, Moon CD, Leahy SC, Creevey CJ, Altermann E, Attwood GT, et al. Metasecretome-selective phage display approach for mining the functional potential of a rumen microbial community. BMC Genomics. 2014;15:356.
24. Shi W, Moon CD, Leahy SC, Kang D, Froula J, Kittelmann S, et al. Methane yield phenotypes linked to differential gene expression in the sheep rumen microbiome. Genome Res. 2014;24:1517-25.

25. Ross EM, Moate PJ, Marett L, Cocks BG, Hayes BJ. Investigating the effect of two methane-mitigating diets on the rumen microbiome using massively parallel sequencing. J Dairy Sci. 2013;96:6030-46.

26. Machmüller A, Soliva CR, Kreuzer M. Effect of coconut oil and defaunation treatment on methanogenesis in sheep. Reprod Nutr Devel. 2003:43:41-55.

27. Zhou M, Hernandez-Sanabria E, Guan LL. Assessment of the microbial ecology of ruminal methanogens in cattle with different feed efficiencies. Appl Environ Microbiol. 2009;75:6524-33.

28. Popova M, Martin C, Eugène M, Mialon MM, Doreau M, Morgavi DP. Effect of fibre- and starch-rich finishing diets on methanogenic Archaea diversity and activity in the rumen of feedlot bulls. Anim Feed Sci Technol. 2011;166-167:113-21.

29. Rooke JA, Wallace RJ, Duthie C-A, McKain N, de Souza SM, Hyslop JJ, et al. Hydrogen and methane emissions from beef cattle and their rumen microbial community vary with diet, time after feeding and genotype. $\mathrm{Br} J$ Nutr. 2014;112:398-407.

30. Wallace RJ, Rooke JA, Duthie C-A, Hyslop JJ, Ross DW, McKain N, et al. Archaeal abundance in post-mortem ruminal digesta may help predict methane emissions from beef cattle. Sci Rep. 2014:4:5892.

31. Wixon J, Kell D. The Kyoto encyclopedia of genes and genomes-KEGG. Yeast. 2000;17:48-55.

32. Ragsdale SW. Enzymology of the acetyl-CoA pathway of $\mathrm{CO} 2$ fixation. Crit Rev Biochem Molr Biology. 1991;26:261-300.

33. Doukov TI, Iverson TM, Seravalli J, Ragsdale SW, Drennan CL. A Ni-Fe-Cu center in a bifunctional carbon monoxide dehydrogenase/acetyl-CoA synthase. Science. 2002;298:567-72.

34. Gagen EJ, Denman SE, Padmanabha J, Zadbuke S, Al Jassim R, Morrison M, et al. Functional gene analysis suggests different acetogen populations in the bovine rumen and tammar wallaby forestomach. Appl Environl Microbiol. 2010;76:7785-95.

35. Punta M, Coggill PC, Eberhardt RY, Mistry J, Tate J, Boursnell C, et al. The Pfam protein families database. Nucl Acids Res. 2012;40(Database issue):D290-301.

36. Altschul SF, Gish W, Miller W, Myers EW, Lipman DJ. Basic local alignment search tool. J Mol Biol. 1990;215:403-10.

37. Richardson EJ, Escalettes F, Fotheringham I, Wallace RJ, Watson M. Meta4: a web application for sharing and annotating metagenomic gene predictions using web services. Frontiers Genet. 2013;4:168.

38. Murray RM, Bryant AM, Leng RA. Rates of production of methane in the rumen and large intestine of sheep. Br J Nutr. 1976;36:1-14.

39. Zhou M, Hernandez-Sanabria E, Guan LL. Characterization of variation in rumen methanogenic communities under different dietary and host feed efficiency conditions, as determined by PCR-denaturing gradient gel electrophoresis analysis. Appl Environ Microbiol. 2010;76:3776-86.

40. Thauer RK, Kaster A-K, Seedorf H, Buckel W, Hedderich R. Methanogenic archaea: ecologically relevant differences in energy conservation. Nature Rev Microbiol. 2008:6:579-91.

41. Janssen PH, Kirs M. Structure of the archaeal community of the rumen. Appl Environ Microbiol. 2008;74:3619-25.

42. Neijssel OM, Teixeira de Mattos MJ. The energetics of bacterial growth: a reassessment. Mol Microbiol. 1994;13:172-82.

43. Hobson PN, Wallace RJ. Microbial ecology and activities in the rumen: Part II. Critical Rev Microbiol. 1982:9:253-320.

44. Schönheit P. Bioenergetics and transport in methanogens and related thermophilic archaea. In: Kates M, Kushner DJ, Matheson AT, editors. The biochemistry of archaea (archaebacteria). London: Elsevier Science Publishers; 1993. p. 113-72

45. Janssen $\mathrm{PH}$. Influence of hydrogen on rumen methane formation and fermentation balances through microbial growth kinetics and fermentation thermodynamics. Anim Feed Sci Technol. 2010;160:1-22.

46. Tymensen LD, McAllister TA. Community structure analysis of methanogens associated with rumen protozoa reveals bias in universal archaeal primers. Appl Environ Microbiol. 2012;78:4051-6.

47. Kittelmann S, Seedorf H, Walters WA, Clemente JC, Knight R, Gordon JI, et al. Simultaneous amplicon sequencing to explore co-occurrence patterns of bacterial, archaeal and eukaryotic microorganisms in rumen microbial communities. PLoS One. 2013:8:e47879. 
48. Yarlett N, Coleman GS, Williams AG, Lloyd D. Hydrogenosomes in known species of rumen entodiniomorphid protozoa. FEMS Microbiol Lett. 1984;21:15-9.

49. Kittelmann S, Pinares-Patiño CS, Seedorf H, Kirk MR, Ganesh S, McEwan JC, et al. Two different bacterial community types are linked with the low-methane emission trait in sheep. PLoS One. 2014;9:e103171.

50. Ramirez-Farias C, Slezak K, Fuller Z, Duncan A, Holtrop G, Louis P. Effect of inulin on the human gut microbiota: stimulation of Bifidobacterium adolescentis and Faecalibacterium prausnitzii. Br J Nutr. 2009;101:541-50.

51. Stewart CS, Flint HJ, Bryant MP. The rumen bacteria. In: Hobson PN, Stewart CS, editors. The rumen microbial ecosystem. London: Chapman and Hall; 1997. p. 10-72.

52. Pope PB, Smith W, Denman SE, Tringe SG, Barry K, Hugenholtz P, et al. Isolation of Succinivibrionaceae implicated in low methane emissions from Tammar wallabies. Science. 2011;333:646-8.

53. Pope PB, Denman SE, Jones M, Tringe SG, Barry K, Malfatti SA, et al. Adaptation to herbivory by the Tammar wallaby includes bacterial and glycoside hydrolase profiles different from other herbivores. Proc Natl Acad Sci. 2010;107:14793-8.

54. Howard BH, Hungate RE. Desulfovibrio of the sheep rumen. Appl Microbiol. 1976:32:598-602.

55. Huisingh J, McNeill JJ, Matrone G. Sulfate reduction by a Desulfovibrio species isolated from sheep rumen. Appl Microbiol. 1974;28:489-97.

56. Counotte GHM, Prins RA. Regulation of rumen lactate metabolism and the role of lactic acid in nutritional disorders of ruminants. Vet Sci Commun. 1978;2:277-303.

57. Henning PH, Horn $\mathrm{CH}$, Steyn DG, Meissner HH, Hagg FM. The potential of Megasphaera elsdenii isolates to control ruminal acidosis. Anim Feed Sci Technol. 2010;157:13-9.

58. Jumas-Bilak E, Jean-Pierre H, Carlier J-P, Teyssier C, Bernard K, Gay B, et al Dialister micraerophilus sp. nov. and Dialister propionicifaciens sp. nov., isolated from human clinical samples. Int J System Evol Microbiol. 2005:55:2471-8.

59. Lana RP, Russell JB, Van Amburgh ME. The role of $\mathrm{pH}$ in regulating ruminal methane and ammonia production. J Anim Sci. 1998;76:2190-6.

60. Russell JB. The importance of $\mathrm{pH}$ in the regulation of ruminal acetate to propionate ratio and methane production in vitro. J Dairy Sci. 1998;81:3222-30.

61. Downes J, Vartoukian SR, Dewhirst FE, Izard J, Chen T, Yu WH, et al. Pyramidobacter piscolens gen. nov., sp. nov., a member of the phylum 'Synergistetes' isolated from the human oral cavity. Int J Syst Evol Microbiol. 2009;59:972-80.

62. Nakazawa F, Sato M, Poco SE, Hashimura T, Ikeda T, Kalfas S, et al. Description of Mogibacterium pumilum gen. nov., sp. nov. and Mogibacterium vescum gen. nov., sp. nov., and reclassification of Eubacterium timidum (Holdeman et al. 1980) as Mogibacterium timidum gen. nov., comb. nov. Int J Syst Evol Microbiol. 2000;50:679-88.

63. McDonald IR, Bodrossy L, Chen Y, Murrell JC. Molecular ecology techniques for the study of aerobic methanotrophs. Appl Environ Microbiol. 2008;74:1305-15.

64. Wang F-P, Zhang Y, Chen Y, He Y, Qi J, Hinrichs K-U, et al. Methanotrophic archaea possessing diverging methane-oxidizing and electron-transporting pathways. ISME J. 2014;8:1069-78.

65. Ministry of Agriculture Fisheries and Food. The analysis of agricultural materials : a manual of the analytical methods used by the Agricultural Development and Advisory Service. 3rd ed. London: HMSO; 1986.

66. DeSantis TZ, Hugenholtz P, Larsen N, Rojas M, Brodie EL, Keller K, et al. Greengenes, a chimera-checked 165 rRNA gene database and workbench compatible with ARB. Appl Environ Microbiol. 2006;72:5069-72.

67. Shannon CE. A mathematical theory of communication. Bell System Technical Journal. 1948;27:379-423.

68. Chao A. Nonparametric-estimation of the number of classes in a population. Scand J Statist 1984;11:265-70.

69. Wold S. PLS for multivariate linear modelling. In: van de Waterbeemd H, editor. Chemometric Methods in Molecular Design. Weinheim: VCH; 1994.

70. Namiki T, Hachiya T, Tanaka H, Sakakibara Y. MetaVelvet: an extension of Velvet assembler to de novo metagenome assembly from short sequence reads. Nucl Acids Res. 2012;40:e155.

71. Seemann T. Prokka: rapid prokaryotic genome annotation. Bioinformatics. 2014;30:2068-9.

72. Eddy SR. A new generation of homology search tools based on probabilistic inference. Genome Inform. 2009;23:205-11.

\section{Submit your next manuscript to BioMed Central and take full advantage of:}

- Convenient online submission

- Thorough peer review

- No space constraints or color figure charges

- Immediate publication on acceptance

- Inclusion in PubMed, CAS, Scopus and Google Scholar

- Research which is freely available for redistribution

Submit your manuscript at www.biomedcentral.com/submit 